\title{
Berichtigungen zU VoL. XV
}

\section{S. 86, 15. Zeile v. u.}

lies: $X_{1}^{*}-E_{\tau}^{*}-S_{1}^{*}$

statt: $-E_{\tau}^{*}-S_{1}^{*}$.

Berichtigungen zU Vol. XIV

S. 423, Théorème:

lies: dont tout sous-espace vectoriel de dimension algébrique dénombrable est métrisable statt: dont toute partie séparable est métrisable.

S. 423 , Z. 13 v. u.

lies: et si tout sous-espace vectoriel de dimension algébrique dénombrable est métrisable statt: et s'il est séparable. 